\title{
Vouchers in U.S. vocational training programs: an overview of what we have learned
}

\author{
Burt S. Barnow
}

Published online: 19 March 2009

(C) Institut für Arbeitsmarkt- und Berufsforschung 2009

\begin{abstract}
An important decision that must be made in operating training programs targeted toward disadvantaged workers is whether the programs dictate the specific training programs that participants will take or they issue vouchers that permit participants to select their specific training programs. Over the past 40 years, the United States has operated a number of targeted training programs, some of which have used vouchers and voucher-like instruments to let participants determine their programs. This paper reviews the evidence from the U.S. experience. Although vouchers permit maximum consumer choice and reduce the need for government oversight, vouchers may not lead to optimal results due to imperfect information and a divergence between government and participant goals. Although vouchers are generally popular with participants, evaluations of U.S. training programs for poor workers and dislocated (displaced) workers show mixed results: many studies indicate that the impact of programs with vouchers is often lower than for programs without vouchers for poor participants, and the evidence is mixed for dislocated workers. When vouchers are used, appropriate counseling and assessment as well as the provision of provider performance information can improve the results.
\end{abstract}

Paper prepared for conference "Vouchers, Contracting Out, and Performance Standards," October 24 and 25, 2008 in Nuremberg, Germany.

B. S. Barnow ( $)$

Johns Hopkins University, Institute for Policy Studies,

Baltimore MD, USA

e-mail: barnow@jhu.edu
Gutscheine in US-amerikanischen Weiterbildungsprogrammen: Überblick der bisherigen Ergebnisse

Zusammenfassung Eine wichtige Entscheidung, die bei der Durchführung von Weiterbildungsmaßnahmen für benachteiligte Arbeitnehmer getroffen werden muss, betrifft den Umfang, in dem die spezifischen Weiterbildungsmaßnahmen für die Teilnehmer durch das Programm festgelegt werden beziehungsweise die Frage, ob die Teilnehmer Gutscheine erhalten sollen, die ihnen selbst die Wahl der Maßnahme überlassen. Im Laufe der vergangenen 40 Jahre wurde in den USA eine Reihe von Weiterbildungsprogrammen durchgeführt, einige davon unter Verwendung von Gutscheinen oder gutscheinähnlichen Mitteln, mit denen die Teilnehmer ihre Weiterbildungsmaßnahmen selbst bestimmen konnten. In dieser Arbeit werden die US-amerikanischen Erfahrungen auf diesem Feld ausgewertet. Obwohl Gutscheine dem Verbraucher ein Maximum an Wahlmöglichkeiten bieten und die Notwendigkeit staatlicher Aufsicht verringern, führen sie aufgrund unzureichender Informationen und der Abweichung zwischen den staatlichen Zielen und denen des Teilnehmers nicht unbedingt zu optimalen Ergebnissen. Evaluationen von Weiterbildungsprogrammen für sozial benachteiligte und freigesetzte Arbeitnehmer führten zu gemischten Ergebnissen. Viele der Studien ließen erkennen, dass trotz der allgemeinen Beliebtheit von Gutscheinen auf Teilnehmerseite die Wirksamkeit von Gutscheinprogrammen für sozial benachteiligte Teilnehmer oft geringer ist als für Gruppen ohne Gutscheine. Bei den freigesetzten Arbeitnehmern sind die Befunde gemischt. Wenn bei ihnen Gutscheine verwendet werden, können die richtige Beratung und Beurteilung sowie Angaben über die Leistungen des Anbieters ihre Leistung verbessern. 


\section{Introduction}

This paper provides an assessment of the use of vouchers for government sponsored targeted training programs in the United States. This section of the paper provides background by defining training, giving the rationale for government involvement in training, and describing the roles that government can play in training programs. The next two sections present the arguments for and against the use of vouchers for government sponsored targeted training programs. The antepenultimate section summarizes the current U.S. employment and training system. The penultimate section summarizes the evidence on how well vouchers and voucher-like programs have performed, and the final section presents conclusions and an assessment of the voucher provisions in recently enacted and proposed legislation.

The term "occupational training" is used in this paper to cover course work, either full- or part-time, that is directly related to preparation for paid employment or to additional preparation for a career requiring other than a baccalaureate or advanced degree. ${ }^{1}$ This definition excludes such employment and training activities as basic skills training, labor exchange services, and public service employment.

The focus of the paper is on targeted training programs, where the targeting is based on economic circumstances (such as low income or welfare status), demographic characteristics (such as being a Native American or older worker), or the circumstances surrounding unemployment (individuals with disabilities or dislocated workers). The intent is to limit the scope of the paper by eliminating programs for the general population such as vocational education. In addition, this paper does not cover training programs focused on people with disabilities, such as the vocational rehabilitation program or the Ticket to Work program, and it does not cover broader voucher-like programs such as Pell grants.

The rationales for government involvement in training are similar to those for education (Barnow 2000b). First, the market for training might not operate efficiently, particularly for the economically disadvantaged, because access to capital is not available for individuals with low incomes and limited assets. Second, training might be considered a "merit good," which society might wish to make widely available without charge. Third, the government might wish to make training available to individuals with certain characteristics as a matter of equity, either to compensate them for individual losses or to enable them to compete better in the labor market. Fourth, workers might underinvest in training from a social perspective either because of imperfect information,

\footnotetext{
${ }^{1}$ This definition is based loosely on the definitions of vocational education from Snyder et al. (2008).
}

a divergence between the private and social discount rates, or because of externalities.

If the government is to be involved in the market for training, there are a number of roles it can play. At one extreme, the government can provide training directly; two good examples of direct provision are the training of pilots and other specialists in the military and the provision of primary and secondary public education. With direct provision, the government is involved in all aspects of the training - recruiting, eligibility determination, selection (if there is excess demand), assessment, assignment to a specific training program, provision of training, and placement at completion. The front-end activities - recruiting, eligibility determination, selection, and assessment - can be undertaken by the responsible government program itself, delegated to a lower level of government, or contracted out.

Vouchers, in a training program context, may be used for any or all of these activities. Under an extreme version, once an individual is admitted to the program, he or she would receive one or more voucher certificates that could be used at vendors for assessment (which could be mandatory or optional), training, and placement. A number of restrictions could be placed on the vouchers:

- The vouchers could be restricted to vendors that meet certain criteria in terms of quality of training (e. g., curriculum used or placement rates).

- The vouchers could be restricted to particular occupations (e. g., occupations with strong current or projected demand and/or with high wages).

- The vouchers could be restricted to occupations for which the participant has shown appropriate aptitude and interest through the assessment.

- The vouchers could be restricted in how much tuition they cover.

There are some types of training where vouchers are not feasible. For example, when services are directly provided by the government there is no choice in vendors. In addition to direct provision of training, vouchers are also inappropriate as a tool for employer-provided training. For direct provision, efficiency can be encouraged through the use of competition or performance incentive systems. ${ }^{2}$

The success of a training program with vouchers may depend critically on the nature of the vouchers as well as the extent to which the program merely hands out voucher certificates to those who are eligible, as opposed to providing the participants with labor market information and data on the effectiveness of potential vendors. Also

\footnotetext{
${ }^{2}$ See Niskanen (1971) for a discussion of alternative approaches to encouraging efficiency for government-provided services. For an assessment of the performance management system for government training programs, see Barnow (2000a), Heckman et al. (2002), and Barnow and Smith (2004).
} 
important is the degree to which the program provides assessment and career guidance to participants. When we look below at the success of training programs with vouchers and voucher-like designs, it is important to look at the services that go along with the voucher. Provision of information and guidance may be particularly important for some of the more disadvantaged populations served by some programs.

\section{The rationale for vouchers}

The case for vouchers in training programs is similar to the case for vouchers in education. Economists tend to favor vouchers over direct provision of training because vouchers maximize consumer choice. If consumers can select the training program they value most, it will generally maximize consumer utility and social welfare. Another potential advantage of vouchers is that they simplify the training process. Instead of a government agency trying to determine the most appropriate training program for a participant and arranging for the training, in the extreme case all the agency needs to do is provide the participant with a voucher and perhaps a list of acceptable training programs. Vouchers may also improve the performance of training organizations. By forcing training organizations to compete for participants, inefficient providers should be driven from the market, resulting in survival of the fittest.

Vouchers fit well with the "reinventing government" movement that was popular in the United States in the 1990s. Three of the principles stressed by Osborne and Gaebler (1992) in their book on reinventing government are "empowering rather than serving," "injecting competition into service delivery," and "meeting the needs of the customer, not of the bureaucracy" (see Chapters 2, 3, and 6 in Osborne and Gaebler 1992). Osborne and Gaebler argue that governments should give decision making power back to the citizens: "What Americans do hunger for is more control over matters that directly affect their lives: public safety, their children's schools, the developers who want to change their neighborhood." (p. 74). Osborne and Gaebler stress the importance of customer choice and specifically call for vouchers in training programs:

The single best way to make public service providers respond to the needs of their customers is to put resources in the customers' hands and let them choose. All the listening techniques listed above are important, but if the customers do not have a choice of providers - schools, training programs, motor vehicle offices - they remain dependent on the goodwill of the provider (p. 180).

The Employment and Training Administration (ETA), which is responsible for targeted training programs, has included customer choice as one of its values since 1993, when ETA began referring to participants in their training programs as customers.

\section{The arguments against vouchers for training programs}

It is no accident that until recently vouchers were rarely used in the United States for targeted training programs. For almost every argument as to why vouchers are appealing, there is an argument to the contrary. First, the basic argument that increasing choice always increases utility can be challenged. If choice is such a good option, why not give people cash and let them decide if they want training or would rather spend the money on food, shelter, or something else? ? $^{3}$

Another rationale for interfering with consumer choice in selecting training programs is that the participants might not make the "right" choice from a social perspective. There are several reasons why consumers might not choose efficiently. First, although the taxpayers' goal is (most likely) for the participant to maximize earnings gains, the participant may select a training program that provides more consumption value, or the participant might select an occupation that provides more consumption and less income than is socially desired.

Another potential problem with consumer choice is that participants in training programs may lack information about the labor market prospects for particular occupations or the success of specific training vendors with participants with their characteristics. Note that there are three different types of potential information failure here: Participants may lack labor market information about occupations in demand and wages that are paid; they may lack information about how successful various vendors are in placing their participants; or they may misperceive their capabilities for various occupations and training programs. The first two information failures can be dealt with by providing information to the participants, but the third requires an assessment of aptitudes and interests as well as guidance to the participants.

\section{Federally sponsored targeted employment and training programs}

While there are a large number of targeted training programs currently supported by the U.S. government, there is some disagreement regarding how many federally sponsored

\footnotetext{
${ }^{3}$ See Garfinkel (1973) for a discussion of the rationale for non-cash bene-
} fits. 
training programs exist. ${ }^{4}$ The General Accounting Office (1995) counted 163 employment and training programs, but the GAO definition of a "program" is very loose. Their definition includes as programs demonstrations with a limited lifespan (such as the Job Training for the Homeless Demonstration), and funding streams used to reward good performance (in JTPA). Barnow and Aron (1989) identified 14 major training programs, but several of those programs are more employment than training programs (e.g., the Senior Community Service and Employment Program or SCSEP) and others no longer exist (the Aid to Families with Dependent Children (AFDC) Work Incentive Program (WIN)). More recently, Mikelson and Nightingale (2004) documented expenditures by the public and private sectors on training. They conclude that in 2002 , between $\$ 3.2$ billion and $\$ 5.3$ billion was spent on job training by the federal government, with roughly one-third by the Department of Labor, one-third by the Department of Education's Pell Grants program, and one-third by numerous smaller programs in five other federal departments. Mikelson and Nightingale (2004) find that states spend another $\$ 500$ to $\$ 700$ million, and that the private sector spends roughly $\$ 50$ billion on training annually.

I focus below on the Workforce Investment Act (WIA) programs for adults and dislocated workers. The WIA programs are highly targeted, and the programs for adults and dislocated workers make use of vouchers, but the youth program does not. ${ }^{5}$ WIA is based on seven guiding principles, most of which have now been adopted by state and local workforce development systems:

- Streamlined services. Integrating multiple employment and training programs at the "street level" through the One-Stop delivery system to simplify and expand access to services for job seekers and employers.

- Individual empowerment. Empowering individuals to obtain the services and skills they need to enhance their employment opportunities through Individual Training Accounts (ITAs), which enable eligible participants to choose the qualified training program that best meets

\footnotetext{
${ }^{4}$ Focus here is on training programs sponsored by the U.S. Department of Labor. I exclude programs that are untargeted, such as vocational education, and programs that do not provide or emphasize training, such as the employment service, which primarily provides labor exchange services, and the Senior Community Service Employment Program (SCSEP), also known as the Older Workers program, because it primarily provides employment opportunities. Also excluded are training programs for people with disabilities, such as vocational rehabilitation and the Ticket to Work program, and training programs operated through welfare programs, such as Temporary Assistance for Needy Families (TANF).

${ }^{5}$ WIA is not completely targeted. The universal access discussed below applies to core and intensive services, but training is restricted to low-income individuals if there are not sufficient resources to serve all customers.
}

their needs. The development of "consumer reports," containing information for each training provider, allows individuals to make informed training choices.

- Universal access. Granting access to every individual through the One-Stop delivery system to core employment-related services. Customers can obtain job search assistance as well as labor market information about job vacancies, the skills needed for occupations in demand, wages paid, and other relevant employment trends in the local, regional, and national economy.

- Increased accountability. Holding states, localities, and training providers accountable for their performance.

- A strengthened role for local Workforce Investment Boards (WIBs) and the private sector. Local boards are business-led "boards of directors" for the local areas.

- Enhanced state and local flexibility. Giving states and localities the flexibility to build on existing reforms to implement innovative and comprehensive workforce investment systems. Through such mechanisms as unified planning and waivers, states and their local partners have the flexibility to tailor delivery systems to meet the particular needs of individual communities.

- Improved youth programs. Linking youth programs more closely to local labor market needs and the community as a whole, and providing a strong connection between academic and occupational learning. In addition, traditional employment and training services are augmented by an array of youth development activities.

Major changes to workforce development programs authorized under Title I of WIA include the following:

- Fostering more coordinated, longer-term planning for workforce development programs. The long-term planning was not only for WIA, but also, on a discretionary basis, for the Employment Service (labor exchange services supported under the Wagner-Peyser Act), and closely related funding streams such as Temporary Assistance for Needy Families (TANF) work programs, Adult Education and Family Literacy, career and technical education (vocational education), and Vocational Rehabilitation programs.

- Institutionalizing One-Stop Career Centers as the cornerstones of the local workforce delivery system. All states applied for and received One-Stop infrastructure grants (financed by national WagnerPeyser Act funds) in the 1990s, some considerably earlier than others. These grants promoted and financed voluntary One-Stop approaches to workforce service delivery. WIA relies on One-Stop Career Centers as the "front-end" of the local workforce system; partners are required to contribute a portion of their funds to support the One-Stop Career Centers' infrastructure. 
- Sequencing job seekers' services from core to intensive to training services. Initially, state and local workforce boards perceived the statutory language and guidance from the U.S. Department of Labor's Employment and Training Administration (USDOL ETA) as encouragement to pursue rigid service sequencing under "work-first" approaches similar to TANF work programs. USDOL ETA, however, did not interpret the sequencing requirement to be synonymous with a work-first approach and sought to clarify its implementation directives accordingly after the first year.

- Implementing universal eligibility for core services via the One-Stop Career Centers. In a departure from its predecessor, JTPA, WIA is structured to provide core services to all participants in the labor market. Training funds, however, are reserved for low-income individuals if there are insufficient funds to serve all customers.

- Increasing reliance on market mechanisms by 1) delivering training services using vouchers called Individual Training Accounts (ITAs) that allow customers to select training from an Eligible Training Provider list supplemented by a "consumer report card" that includes provider performance information, and 2) linking performance incentives to program standards for three programs: WIA, Adult Education and Family Literacy, and Vocational Education.

The changes that WIA made to the workforce system in 1998 stem from a number of trends that had been underway for several years in the states as well as at the federal level. Many welfare and workforce programs adopted an aggressive work-first philosophy, where participants were expected to obtain a job quickly rather than collecting cash welfare benefits or participating in more substantive education and training designed to enhance skill levels. States began to stress individual responsibility for workforce programs' participants. Individuals and their families were expected to play an expanded role in their career and job development, including arranging education and training services' financing (see National Governors Association 2002). States also began emphasizing consumer choice through voucher-based training approaches that allowed participants to select occupations and specific training providers within approved guidelines (see Trutko and Barnow 1999).

As discussed by Barnow and King (2000), the USDOL facilitated WIA's implementation by fostering and financing the One-Stop delivery system's creation. The USDOL also launched supporting initiatives in the years leading up to WIA, including enhanced labor market information availability and access through America's Labor Market Information System (ALMIS) initiative and informed consumer choice tools such as consumer report cards on program outcomes and voucher-based service delivery approaches.

\section{Evidence on vouchers for targeted training programs}

In spite of the theoretical appeal of vouchers for targeted training programs, there is surprisingly little evidence on how effective vouchers are relative to alternative service delivery mechanisms. I use the term voucher loosely here and include examples where participants are primarily responsible for selecting their training programs. This section summarizes the evidence on the effectiveness of vouchers for training programs for the economically disadvantaged and dislocated workers.

\subsection{Evidence on vouchers for training programs} for the economically disadvantaged

I identified two experimental efforts that rigorously examined the effectiveness of vouchers for disadvantaged populations - a voucher experiment that was conducted in conjunction with the Seattle-Denver income maintenance experiments in the 1970s and a more recent experiment where the degree of authority given to WIA customers was randomly varied. WIA made the use of vouchers mandatory for most customers receiving training, and one study reviewed the use of vouchers under JTPA when the use of vouchers was a local option. There were two qualitative assessments of the use of vouchers under WIA.

\subsubsection{Evidence from the Seattle-Denver voucher experiment}

The Counseling and Education Subsidy Program (CESP) was implemented along with the Seattle-Denver Income Maintenance Experiments (often referred to as SIME/ DIME). SIME/DIME was the largest and last of a series of experiments that were conducted in the 1960s and 1970s to learn about the feasibility and behavioral implications of a "negative income tax" program where members of the treatment group were provided a guaranteed income and any income earned by the participants was taxed at a specified rate. The SIME-DIME program was carried out between 1970 and 1978 in selected sections of Seattle and Denver. To be eligible for the program, a person had to meet the following requirements:

- Family income: below $\$ 9,000$ (in then-current dollars) for a family of size of four (adjusted for other family sizes).

- Family structure: restricted to married couples and single parents with minor dependent children.

- Race/ethnicity: family head had to be black or white in Seattle, and black, white, or Chicano in Denver.

- Characteristics of family head: between the ages of 18 and 58, capable of employment, and not in military service. 
For the counseling and education subsidy component of the experiment, treatment and control group members were randomly assigned to one of three counseling and training options:

- Counseling only;

- Counseling plus a 50 percent subsidy for the cost of any education or training in which the person enrolled; or

- Counseling plus a full subsidy for the cost of any education or training in which the person enrolled (see Christopherson 1983 for more details).

Participants were enrolled in the experiment for up to six years. Education was interpreted very broadly so that most occupational training and general education courses were approved; most of the training was occupational classroom training, and the community college was the most common provider. Participation in subsidized training was moderate. For the group with a 100 percent subsidy, about 36 percent of the married men and women participated, and 47 percent of the single female heads of household took some education or training. Participation rates were lower for those granted a 50 percent subsidy -21 percent for the married men and women, and 35 percent for the single female heads.

The hypothesis underlying the CESP was that the subsidies for training would lead to increased participation in education and training programs which would, in turn, increase earnings. The first part of the hypothesis was confirmed, with participants in the 100 percent subsidy group taking approximately one year of additional training compared to those with no subsidy. The surprising result was that in virtually all the analyses undertaken, the training led to either no change in subsequent earnings or an actual reduction in earnings, although the negative impacts were often not statistically significant. Dickinson and West (1983, p. 283) conclude:

Up to this point we have found that, as expected, the SIME/DIME counseling and training programs increased the amount of job counseling and the amount of additional schooling received. However, we have determined they also, quite unexpectedly, reduced the earnings of those eligible to participate, with the exception of the counseling-only program for single women. Further, we have found that these negative impacts are widespread and that the programs, on the whole, were not beneficial even for select subgroups of the population (again, with the exception of counseling only for single women). Since these results are based on a comparison of randomly assigned experiments and controls and thus are not a result of the self-selection and noncomparability problems that plague most other evaluations of employment and training programs, considerable reliance can be placed on these basic findings.
Dickinson and West undertook a number of analyses to determine if their findings resulted from some type of statistical problem or non-random selection. In the end, they concluded that the problem was in the treatment itself:

The SIME/DIME programs were designed to maximize freedom of choice for participants. They offered nondirective counseling and a wide range of educational opportunities. Evaluation indicates that such programs in general are inappropriate for low-income individuals, causing at least some of them to form unrealistic expectations about their labor market prospects and to pursue overly ambitious goals. (Dickinson and West 1983, p. 253)

\subsubsection{Evidence from the job training partnership act (JTPA)}

The Job Training Partnership Act was the predecessor to the Workforce Investment Act (WIA), providing employment and training services to disadvantaged adults, dislocated workers, and youth from 1983 through 2000. Vouchers were not required under JTPA, but, as noted above, the 1998 WIA legislation mandated the use of vouchers called individual training accounts (ITAs) in most instances of training provided to disadvantaged adults and dislocated workers. WIA was enacted in August 1998, but states and local workforce areas did not have to make the transition to the new program until July 1, 2000. During this period, DOL funded Capital Research Corporation to analyze the experience of local programs that used vouchers for their JTPA programs.

Trutko and Barnow (1999) conducted site visits and telephone interviews with nine sites that used vouchers under JTPA. The study found that the sites were generally pleased with the use of vouchers so long as they could have some authority on the structure and use of the vouchers. Key findings from the study include:

- Eight of the 9 sites had "constrained choice" individual referral or voucher-like approaches. These voucher-like systems usually featured:

- assessment/counseling to determine appropriate training for the participant;

- job training limited to high-demand occupations;

- screening of vendors for quality and cost of training, as well as satisfactory job placement rates;

- joint decision-making between the participant and JTPA counselor on selection of training and vendor; and

- Issuance of time-limited training authorization.

- One site had a "pure" voucher, in which funds were placed in an individual account referred to as the "Tool Chest," which operated like a checking account against 
which customers could draw funds for training and a range of other services.

- Some workforce development agencies placed dollar limits on training expenditures. Six agencies established limits on overall training expenditures per participant (ranging from $\$ 2,000$ to $\$ 10,000$ per participant); the other three agencies did not have specific per-participant expenditure limits.

- Time limits were placed on use of vouchers or training authorizations. Agencies limited the time under which individuals were to complete training, generally to two years or less. In addition, agencies usually authorized training expenditures for only a single term or semester. Training authorizations or vouchers usually listed specific items (e. g., courses, registration fees, books, etc.) and provided specific dollar amounts that would be reimbursed to the training provider.

- Payment to the training institution was not contingent on job placement, but in some instances was partially contingent on completion of training.

- Agencies administering voucher or voucher-like systems typically used a screening process to select approved or qualified training vendors based on types of training provided, past performance, costs, and other criteria.

- Most agencies used a Request for Proposal (RFP) or Request for Quotation (RFQ) process, typically soliciting information about the vendor as an organization as well as on specific training programs/courses offered.

- There was considerable variation in the degree of rigor in reviewing and approving vendor applications - e. g., one agency conducted site visits to each vendor with an industry expert and agency official; other agencies basically accepted all vendors except those with very poor track records.

- Some agencies had expedited application and approval processes for new training programs that participants identified (but had not been already certified as a qualified training vendor).

- Most agencies maintained a directory of approved providers, which included basic information about approved training courses offered through the vendor.

Workforce development agencies believed that vouchers had little or no effect on program costs or outcomes, but customer satisfaction was enhanced. Most agency administrators felt the greatest impact of introducing their voucher or voucher-like systems was to expand the range of training programs and vendors from which participants could select. Vouchers also increased participant involvement and empowerment in making training decisions. As a result of greater choice and empowerment to choose vendors, agencies reported high levels of customer satisfaction with voucher systems.

Workforce development agencies also noted generally high levels of acceptance of and satisfaction with vouchers among training vendors in their localities. Training vendors responded generally favorably to vouchers because they were similar to the way in which the general public purchases training from the training facility. Several local programs noted that in comparison to contracting for class-size training, the use of vouchers and voucher-like systems resulted in greater dispersion of training dollars among various training vendors in their communities.

Thus, among the local programs that voluntarily used vouchers under JTPA, the experiences were positive, although, as noted above, the local programs interviewed believed that the vouchers had no impact on cost or outcomes. The major concerns expressed by the local programs in anticipation of the mandatory use of vouchers under WIA were that (1) they wanted to retain the guided choice option to assure that participants did not use vouchers inappropriately and (2) to the extent that the participants had most of the discretion, they did not believe that the program should be held accountable for such customers in their performance calculations. ${ }^{6}$

\subsubsection{Evidence from the workforce investment act}

As noted above, WIA places stronger emphasis than its predecessors on market forces, including the choice of training programs by customers. Specifically, WIA calls for most customers who receive training to do so through voucher-like instruments called individual training accounts (ITAs). The exceptions to the ITA requirement are for on-the-job training (OJT), customized training, when there are community based organizations or other organizations with demonstrated effectiveness in serving special populations with multiple barriers to employment, and when there are too few training vendors available for the ITA approach to work.

The WIA statute and regulations do not, however, call for pure vouchers. First, states are required to establish an eligible training provider (ETP) list that includes training programs that meet state requirements for placement rates and wage rates for WIA and all customers. Second, programs are required to fund training for occupations in high demand, and many states restrict training to occupations with high projected growth by federal, state, or local occupational projections. Third, local programs were permitted to establish cost and time limits for their customers using ITAs.

\footnotetext{
${ }^{6}$ The guided choice option means that the customers received substantial guidance on how they could use their vouchers. The concept is explained in more detail in the next section of the paper.
} 
Finally, local programs were permitted to use "guided choice" in permitting customers to make use of their ITAs.

Two qualitative evaluations of the implementation of WIA were sponsored by DOL, Social Policy Research Associates (SPR 2004) and Barnow and King (2005); both studies reached similar conclusions about the use of vouchers under WIA. Both evaluations noted that because local programs retained the right to use a guided choice strategy, the local programs were not unhappy with the requirement that the customers could choose the vendor they preferred. The SPR study (2004, p. VI-20) concluded that "The general approach of promoting informed choice seemed to be embraced virtually everywhere we visited," while Barnow and King (2005, p. 42) state that "[ITAs] are popular with participants and accepted by the local WIBs as a useful program feature." The evaluations found that local programs varied significantly in how they limited customer choice; for example, SPR found that in the 29 sites they visited, the ITA dollar caps ranged from $\$ 1,200$ to $\$ 10,000$, and four of the sites had no cap. The two studies also found that local sites differed in restrictions on occupations that could be pursued. SPR notes that some local programs permitted training only for occupations with strong occupational growth projections, but others would sometimes permit training for other occupations.

Both evaluations noted problems with the eligible training provider (ETP) list requirement in WIA. Barnow and King (2005, p. 40) concluded that "while a few states found the ETP to be useful and a minimal burden, in most states the providers, the state, or both complained that gathering the data was expensive and not worth the effort." The study notes that in many instances there were too few WIA customers to provide statistically reliable results. The SPR study had similar findings, and both studies noted that many training institutions believed that the effort and expense required to gather the data did not produce commensurate benefits. Neither study concluded that information about providers was not needed, but rather that the current system appeared too expensive for the benefits provided and that efforts should be made to make the system more flexible.

\subsubsection{The individual training account experiment}

The Employment and Training Administration funded an ITA experiment to learn the relative effectiveness of ITAs with different levels of control by the local programs. The experiment involved randomly assigning WIA customers who were about to receive ITAs in eight local areas to one of three options. The evaluation results are presented in McConnell et al. (2006). Under Approach 1, the structured customer choice approach, customers were required to receive counseling provided by the local program, the monetary level of the ITA was set by the local program, and counselors could overrule the training choices of participants. Under Approach 2, the guided customer choice approach, the monetary level of the ITA was fixed, receipt of counseling was mandatory but less intensive than under Approach 1, and the counselors could not reject the customer's choice of providers so long as the program was on the eligible provider list. The key features that distinguish the structured choice approach from the guided choice approach are that under the former, the counselor could determine the size of the ITA for a customer while under the guided choice approach there was a universally fixed amount, and under the structured choice approach the counselor could reject the customer's choice of programs but this was not the case under the guided choice approach. ${ }^{7}$ Under Approach 3, the maximum customer choice approach, the maximum value of the ITA was fixed, counseling was voluntary, and the counselors could not reject the customer's choice of providers so long as the program was on the eligible provider list (McConnell et al. 2006). The experiment included nearly 8,000 customers and operated for slightly more than two years beginning in December 2001.

Customers under all three options were satisfied with the ITA process, but the take-up rate was highest for Approach 3. Customers in Approach 3 were also less likely to request counseling, and they considered fewer training programs than the customers assigned to Approaches 1 and 2. In reporting their findings, McConnell et al. (2006) stress that when one compares Approach 2 with Approach 3 or Approach 2 with Approach 1, there are no significant gains or losses to society. Based on these findings, McConnell et al. (2006) conclude that the Bush Administration's proposed strategy of switching from ITAs administered through the local One-Stop Career Centers to Career Advancement Accounts (CAAs), which would provide vouchers directly to eligible potential customers, would likely lead to some increase in the demand for training but little change in impact.

Although these conclusions appear to be supported by the analyses, there are alternative ways to view the results. If one compares Approach 1 with Approach 3, the earnings gain to participants in the 15 months following random assignment is $\$ 1,308$ higher (statistically significant) for Approach 1 when survey data are used and \$ 462 higher (not statistically significant) when administrative data are used.

\footnotetext{
${ }^{7}$ It should be recognized, as noted earlier in the paper, that vouchers can best be thought of as having a continuum of control by the issuing authority and the recipient. Thus, the "guided choice" model described here should best be thought of as one variation where the issuer retains some authority but the recipient has some discretion as well.
} 
Mean earnings for Approach 1 customers exceed mean earnings for Approach 3 customers each quarter regardless of the source of earnings data, but the differences are rarely statistically significant for an individual quarter and decline over time. Thus, a longer follow-up period would be unlikely to change the findings much. Nonetheless, the findings are consistent with findings from the SIME-DIME experiment conducted 30 years earlier: training participants like having choices, but there may be some cost in terms of earnings impact.

\subsection{Evidence on vouchers for training programs}

for the dislocated workers

There is also evidence available on the effectiveness of vouchers for dislocated workers, in such programs as the Trade Adjustment Assistance (TAA) program, a voucher experiment called the Career Management Account (CMA) that the U.S. Department of Labor tested in 13 sites, and several local programs that used vouchers or voucher-like instruments. ${ }^{8}$

\subsubsection{Trade adjustment assistance}

The Trade Adjustment Assistance (TAA) program was established in 1962 to provide financial assistance and training to workers who lose their jobs as a result of imports. The program provides cash assistance through Trade Readjustment Allowances (TRA), and workers are permitted to identify and select their own training. The program has been amended significantly several times. The qualifying criteria were liberalized in 1974 (see Corson et al. 1993). In 1981, TRA benefits were reduced to be the same as the worker's unemployment insurance (UI) benefits, and workers could collect TRA only after they had exhausted their unemployment insurance. Training was made an entitlement and a requirement for workers on TAA beginning in 1988. Although dislocated workers covered by TAA must have their training approved by the employment service, the workers may choose their own training, and the employment service generally concurs with the workers' plans. Thus, the training component of TAA is essentially a voucher-based training program for dislocated workers who lose their job because of imports. ${ }^{9}$

Mathematica Policy Research (MPR) completed an impact evaluation of TAA training in 1992. The evaluation included four groups of TAA recipients: participants who

\footnotetext{
${ }^{8}$ In the United States the terms "dislocated workers" and "displaced workers" are used synonymously.

${ }^{9}$ The TAA program has been modified several times since the Corson et al. (1993) evaluation, and a new impact evaluation using random assignment is currently underway.
}

began receiving TRA benefits prior to the 1988 changes, participants who received TAA training prior to the 1988 changes, participants who began receiving TRA payments after the 1988 changes, and participants who enrolled in TAA training after the 1988 changes. The original design called for 15 states to be included in the study, but six states refused to participate and only one was replaced, yielding a final sample of 10 states. For comparison groups, the MPR researchers selected samples of UI recipients matched to the TAA samples on several criteria. The UI samples were drawn from the same states and roughly the same time periods as the TAA and TRA samples. The UI samples were drawn from manufacturing because the TAA population is drawn largely from manufacturing ( 85 percent in the TAA sample selected). Finally, because workers had to exhaust their UI payments to collect TRA, the analysis was restricted to UI exhaustees. The final analysis sample included 4,776 individuals, of whom 1,174 were UI exhaustees and the remainder were TRA recipients and TAA trainees. Data were gathered primarily through telephone interviews and covered approximately four years of experience.

The MPR study found that a substantial minority of TAA participants received training - 37 percent in the pre-1988 sample (when training was neither an entitlement nor a requirement) and 47 percent in the post- 1988 period. ${ }^{10}$ About 70 percent of the TAA trainees completed their training, with a slightly higher proportion of the pre-1988 group (72 percent) completing training than in the post1988 group (67 percent). As in most studies of dislocated workers, the MPR study found that participants in TAA generally suffered substantial reductions in wage rates and earnings following their job loss.

The MPR researchers used ordinary least squares regression analysis of the TAA samples and the UI exhaustee comparison group to estimate the impact of TAA training on the employment and earnings of participants. The researchers found that when differences in characteristics between trainees and others are controlled for, "our findings imply that, if training has a substantial positive effect on employment or earnings among all trainees, it is realized not earlier than three years after the initial UI claim" (Corson et al. April 1993, p. 155). In other words, the TAA program had no impact on earnings during the first three post-program years. The study also found that individuals who received training had slightly lower wage rates than those who did not take training, but the differences were generally not statistically significant.

Although the TAA evaluation is another example of a voucher-like program that failed to produce significant

\footnotetext{
${ }^{10}$ Although training was generally required in the post-1988 period, participants could obtain waivers if appropriate training was not available.
} 
positive impacts on the employment and earnings of trainees, the evidence here must be interpreted with caution for several reasons (see Stanley et al. 1998, p. 45). First, the evaluation used a non-experimental design, and the design may not have adequately controlled for differences between the treatment and control groups. ${ }^{11}$ Second, the evaluation may not have followed up the participants long enough to measure any gains. Finally, the failure of the program to produce significant impacts may not have been due to the voucher aspect of the program but to other features of the intervention. For example, in the post-1988 period, training was a requirement, so the results may not apply to a non-mandatory program. It should be noted that several other evaluations of training programs for dislocated workers failed to find significant positive impacts (Stanley et al. 1998, p. 45).

\subsubsection{The career management account demonstration}

The Career Management Account (CMA) Demonstration project was sponsored by the U.S. Department of Labor to learn about the feasibility, impact, and cost-benefit attributes of vouchers for dislocated workers relative to the traditional approach used in Title III of JTPA. The CMA demonstration was conducted in 13 competitively selected sites from 1995 through 1997, and the evaluation was conducted by Public Policy Associates (1998). The sites differed significantly in the treatments offered, the activities and services covered by the vouchers, and in other services and activities offered to participants. Assessing the CMA is difficult because the evaluation mostly compares CMA results to regular Title III results in the 13 sites. Results from the evaluation indicate that participants in the CMA group had an 84 percent positive termination rate, 4 percentage points more than other Title III participants, and that 13 weeks after termination, wages for CMA participants grew by about 4 percent more than for other Title III participants. Surveys and focus groups also provided some positive evidence for the CMA approach. Staff reported satisfaction with the approach and believed that the outcomes were better. CMA participants indicated slightly higher satisfaction than participants in the regular Title III program, but satisfaction levels were high (in excess of 85 percent) in both programs.

In addition to the lack of an experimental design (except in one site), the design of the demonstration makes it difficult to determine how useful the vouchers were in leading

\footnotetext{
${ }^{11}$ Non-experimental designs do not make use of random assignment to generate a control group with similar characteristics. In such designs, the treatment and comparison groups may not be adequately matched, and there is a risk that any impacts detected are an artifact of the design rather than the treatment itself. This is not to say that all non-experimental evaluations are flawed, but simply that the results should be viewed with caution.
}

to the higher positive termination and wage growth rates for the CMA group. The biggest problem is that CMA programs spent significantly more per participant than regular Title III programs -74 percent more. Part of the increased cost was for one-time startup costs, but the evaluators were not able to determine how much more would have been spent on an ongoing basis.

Overall, the findings from the CMA are too mixed to provide policy recommendations. There were small positive outcome differences in favor of the CMA participants, but the cost differentials were potentially large, and the lack of a strong evaluation design leaves open the question of how much any differences are explained by the treatment rather than by selection. Public Policy Associates (1998, p. 93) concludes that "The CMA Demonstration project did not prove that a voucher system is inherently superior to a staffdirected system. Instead, the demonstration seemed to indicate that voucher systems in general are likely to work just as well and, along the way, lead to somewhat happier participants and staff."

\subsubsection{Other dislocated worker findings}

Several local voucher-type programs for dislocated workers have also been evaluated. Bednarzik and Jacobson (1996) provide evidence on a voucher program funded by Allegheny County, Pennsylvania. This program was open to virtually all dislocated workers in the county (which is most of the Pittsburgh metropolitan area). Notable features of the program included a requirement that participants take counseling before using their vouchers and that the vouchers were valid only at the Community College of Allegheny County (CCAC). The training received through the voucher program was estimated to increase earnings by about 6.3 percent, but the estimate is based on a comparison with non-participants rather than participants in an alternative program, and the evaluation uses non-experimental methods so it is possible that the estimates are biased.

\section{Conclusions about vouchers for targeted training programs}

Interestingly, vouchers have not generated as much spirited debate for targeted training programs as they have for education. In reviewing the theory and evidence for vouchers, the picture is mixed, with arguments for and against vouchers. Three main conclusions can be drawn from the literature. Conclusion 1: Although there are good arguments in
favor of vouchers as a delivery mechanism for targeted
training programs, there are also good reasons why 
authority for determining the type of training and vendor should be vested in the government.

The theoretical case for vouchers rests on the arguments that vouchers maximize choice, thereby increasing utility to consumers, and promote efficiency by making vendors compete with each other. On the other hand, for publicly funded programs, interdependent utility functions could result in vouchers leading to less social welfare than programs where assignments are made by the government or its agent. In addition, consumers will act to maximize their private gains, which may not be the same as social gains. Finally, participants in training programs may lack appropriate information about their own skills and aptitudes as well as the characteristics of training vendors. Providing information about placement rates of vendors will help eliminate the latter problem, but it will not deal with the former. Thus, economic theory provides no strong a priori reason to prefer vouchers to a program that involves negotiated decision making between the program and the participant. At a minimum, the evidence suggests that vouchers be restricted to training for which the participants show aptitude and background. This is the approach followed by JTPA programs using the "individual referral" approach, and it is permitted under WIA.

Conclusion 2: Empirical evidence on vouchers is mixed. Previous studies provide mainly negative evidence on the effectiveness of vouchers for the economically disadvantaged and quite mixed evidence on the effects for dislocated workers.

Unfortunately, the empirical evidence on vouchers for targeted training programs is not as strong as one might like. Evidence from the SIME-DIME voucher experiments for the economically disadvantaged is over 20 years old, but it provides substantial evidence that vouchers lead to smaller earnings gains than a more prescriptive approach. The recent ITA experiment findings are consistent with the SIME-DIME findings in showing that vouchers lead to smaller earnings gains than a system where the program has a strong role in assigning the training.

The programs for dislocated workers provide mixed evidence on the utility of vouchers, and none of the evaluations have as strong a design as is desirable. The major evaluation of the Trade Adjustment Assistance (TAA) program, which is essentially a voucher program for dislocated workers who lose their jobs due to imports, showed it to have little impact on the earnings of participants. The negative findings might stem from a weak evaluation design or from the ineffectiveness of training for this group rather than from any characteristics of vouchers. Findings from the Career Management Accounts (CMA) demonstration indicate possible small, positive effects on employment and earnings, but the demonstrations spent significantly more per participant than the regular training programs to which they were compared, and the CMA participants actually received less vocational training than in traditional programs. The mixed findings for dislocated worker training programs might reflect problems with the underlying training intervention itself rather than with the use of vouchers.

Conclusion 3: A targeted training program should include assessment and counseling to determine what training is appropriate for the participants and screening of vendors for quality of training and appropriate placement rates.

All the voucher programs (as well as other programs) that have positive impacts include assessment, counseling, and screening of vendors. The 1992 JTPA amendments required local service delivery areas (SDAs) to provide indepth assessment for Title II-A participants, and most of the SDAs interviewed in the assessment of the amendments stated that although the increased assessment added to the cost and time required to serve participants, the benefits exceeded the costs. Programs using individual referrals under JTPA have found that participants are generally satisfied with the choices they receive, and the programs believe that the outcomes are as effective as with traditional referral mechanisms.

For targeted training programs, vouchers can be useful but they can also be deleterious. The evidence indicates that vouchers alone are insufficient to guarantee that training programs are effective. Research by the General Accounting Office indicates that Pell Gants and guaranteed student loans are being used by students to train for occupations with at least twice as many entrants as there are job openings (see U.S. General Accounting Office 1997.) On the other hand, training programs that do not take the preferences of participants into account are almost certainly doomed if people are enrolled in occupational programs regardless of their interests. For targeted training programs to work well, participant preferences must be taken into account. At the same time, a well-run training program can offer participants the assessment and guidance they are likely to require to assure that the participants can benefit from the training.

In the case of the Workforce Investment Act, the program gives local workforce investment areas the opportunity to guide participants into suitable training opportunities. Thus, WIA appears to strike a good balance between permitting participants to have choice, but restricting their choice set to programs that are likely to benefit them. It is best to consider vouchers as a continuum rather than an all-or-nothing proposition. Providing participants with more control is more satisfying to the customer, but is likely to come at some cost in impact. 


\section{Executive summary}

An important decision that must be made in operating training programs targeted toward disadvantaged workers is whether the programs dictate the specific training programs that participants will take or they issue vouchers that permit participants to select their specific training programs. Over the past 40 years, the United States has operated a number of targeted training programs, some of which have used vouchers and voucher-like instruments to let participants determine their programs. This paper reviews the arguments for and against the use of vouchers for targeted training program and assesses the evidence from the U.S. experience.

The theoretical case for vouchers rests on the arguments that vouchers maximize choice, thereby increasing utility to consumers, and that they promote efficiency by making vendors compete with each other. On the other hand, for publicly funded programs, interdependent utility functions could result in vouchers leading to less social welfare than programs where assignments are made by the government or its agent. In addition, consumers will act to maximize their private gains, which may not be the same as social gains. Finally, participants in training programs may lack appropriate information about their own skills and aptitudes as well as about the characteristics of training vendors. Providing information about placement rates of vendors will help eliminate the latter problem, but it will not deal with the former. Thus, economic theory provides no strong a priori reason to prefer vouchers over a program that involves decision making negotiated between the program and the participant.

Unfortunately, the empirical evidence on vouchers for targeted training programs is not definitive. Evidence from voucher experiments for the economically disadvantaged that were conducted in Seattle and Denver is over 20 years old, but it provides substantial evidence that vouchers lead to smaller earnings gains than a more prescriptive approach. The recent findings from an experiment where the relative control of the program officials versus the participants was varied produced findings that are consistent with the SIME-DIME findings in showing that vouchers lead to smaller earnings gains than a system where the program has a strong role in assigning the training.

Evidence from programs for displaced workers provides mixed evidence on the utility of vouchers, and none of the evaluations has as strong a design as is desirable. The major evaluation of the Trade Adjustment Assistance (TAA) program, which is essentially a voucher program for dislocated workers who lose their jobs due to imports, showed it to have little or no impact on the earnings of participants. The negative findings might stem from a weak evaluation design or from the ineffectiveness of training for this group rather than from any characteristics of vouchers. Findings from the Career Management Accounts (CMA) demonstration indicate possible small, positive effects on employment and earnings, but the demonstrations spent significantly more per participant than the regular training program to which they were compared, and the CMA participants actually received less vocational training than in traditional programs. The mixed findings for dislocated worker training programs might reflect problems with the underlying training intervention itself rather than with the use of vouchers.

All the voucher programs reviewed that have positive impacts include assessment, counseling, and screening of vendors. A new requirement for U.S. training programs in 1992 required local areas to provide in-depth assessment for, and most of the officials interviewed in the assessment of the new requirement stated that although the increased assessment added to the cost and time required to serve participants, the benefits exceeded the costs.

For targeted training programs, vouchers can be useful but they can also be deleterious. The evidence indicates that vouchers alone are insufficient to guarantee that training programs are effective. Though vouchers permit maximum consumer choice and reduce the need for government oversight, vouchers may not lead to optimal results due to imperfect information and a divergence between government and participant goals. Although vouchers are generally popular with participants, evaluations of U.S. training programs for poor workers and dislocated (displaced) workers show mixed results: many studies indicate that the impact of programs with vouchers is often lower than for programs without vouchers for poor participants, and the evidence is mixed for dislocated workers. When vouchers are used, appropriate counseling and assessment as well as the provision of provider performance information can improve the results.

\section{Kurzfassung}

Eine wichtige Entscheidung, die bei der Durchführung von Weiterbildungsmaßnahmen für benachteiligte Arbeitnehmer getroffen werden muss, betrifft den Umfang, in dem die spezifischen Weiterbildungsmaßnahmen für die Teilnehmer durch das Programm festgelegt werden beziehungsweise die Frage, ob die Teilnehmer stattdessen Gutscheine erhalten, die ihnen selbst die Wahl der Maßnahme überlassen. Im Laufe der vergangenen 40 Jahre wurden in den USA eine Reihe von Weiterbildungsprogrammen durchgeführt, einige davon unter Verwendung von Gutscheinen oder gutscheinähnlichen Mitteln, mit denen die Teilnehmer ihre Weiterbildungsmaßnahmen selbst bestimmen konnten. In dieser Arbeit werden die Argumente für und gegen den 
Einsatz von Gutscheinen für gezielte Weiterbildungsprogramme untersucht und die Ergebnisse aus den bisher in den USA gesammelten Erfahrungen beurteilt.

Theoretisch sind Gutscheine zu befürworten, weil sie ein größtmögliches $\mathrm{Maß}$ an Wahlmöglichkeiten zulassen und so sowohl den Nutzen für Verbraucher als auch die Wirtschaftlichkeit verbessern, da sie zu Wettbewerb unter den Schulungsanbietern führen. Andererseits könnten bei staatlich finanzierten Programmen voneinander abhängige Nutzenfunktionen dazu führen, dass solche Gutscheine einen geringeren sozialen Nutzen stiften als Programme, in denen Maßnahmen von staatlicher Seite zugeteilt werden. Außerdem sind Verbraucher bestrebt, ihren individuellen Nutzen so weit wie möglich zu verbessern, was aber nicht notwendigerweise den gesamtgesellschaftlichen Nutzen erhöht. Letztlich können Teilnehmer an Weiterbildungsprogrammen ihre eigenen Fertigkeiten und Fähigkeiten sowie die Maßnahmen der Schulungsanbieter vielleicht auch nicht gut genug einschätzen. Angaben über Vermittlungsquoten der Anbieter können zur Lösung des letzteren Problems, nicht aber der des ersteren beitragen. Daher stellt die Wirtschaftstheorie a priori keinen überzeugenden Grund für die Bevorzugung von Gutscheinen gegenüber einem Programm dar, das eine Abstimmung der Entscheidungen zwischen dem Programm und dem Teilnehmer beinhaltet.

Leider lassen die empirischen Ergebnisse zu Gutscheinen für gezielte Weiterbildungsprogramme keinen endgültigen Schluss zu. Ergebnisse aus Untersuchungen zu Gutscheinen für sozial benachteiligte Personen, die in Seattle und Denver durchgeführt wurden, sind inzwischen über 20 Jahre alt, aber sie liefern deutliche empirische Belege dafür, dass Gutscheine zu geringeren Einkommenszuwächsen führen als ein stärker regulierendes Vorgehen. Neuere Ergebnisse aus einem Experiment, in dem die relative Kontrolle der Programmverantwortlichen gegenüber den Teilnehmern variierte, stimmen mit den Ergebnissen des SIME-DIME-Experimentes in Seattle und Denver überein, nach denen Gutscheine zu geringeren Einkommenszuwächsen führen als ein System, in dem die Schulungsmaßnahmen hauptsächlich durch das Programm festgelegt werden.

Die Ergebnisse zum Nutzen von Gutscheinen bei Programmen für freigesetzte Arbeitnehmer sind gemischt, und in keinem der Fälle war ein ideales Evaluationsdesign gegeben. Die Hauptevaluation des Trade Adjustment Assistance-Programms (TAA), bei dem es sich im Wesentlichen um ein Gutscheinprogramm für freigesetzte Arbeitnehmer handelt, die ihre Arbeitsplätze durch Importe verloren haben, zeigte eine geringe bis keine Auswirkung auf die Einkommen der Teilnehmer. Die negativen Ergebnisse sind möglicherweise eher auf ein schwaches Evaluationsdesign oder die Wirkungslosigkeit der Schulung für diese Gruppe zurückzuführen als auf die Eigenschaften der Gutscheine an sich. Die Ergebnisse aus der Studie „Career Management Accounts“ (CMA) lassen auf mögliche kleine, positive Auswirkungen auf Beschäftigung und Einkommen schließen, wobei aber hier pro Teilnehmer wesentlich größere finanzielle Mittel eingesetzt wurden als bei normalen Schulungsmaßnahmen, die zum Vergleich herangezogen wurden. Außerdem war der Schulungsumfang für die CMA-Teilnehmer sogar geringer als in herkömmlichen Programmen. Die gemischten Ergebnisse für freigesetzte Arbeitnehmer sind unter Umständen eher ein Anzeichen für Probleme mit den Weiterbildungsmaßnahmen selbst als für Probleme beim Einsatz von Gutscheinen.

Alle untersuchten Gutscheinprogramme mit positiven Auswirkungen beinhalten Beurteilungen, Beratung und das Screening von Anbietern. Im Jahr 1992 trat eine neue Anforderung für Weiterbildungsmaßnahmen in den USA in Kraft, nach der regional gründliche Beurteilungen erfolgen mussten. Die meisten der zu dieser neuen Anforderung befragten Personen gaben an, dass, obwohl die zusätzliche Anforderung einen größeren Kosten- und Zeitaufwand mit sich brachte, der Nutzen die Kosten übertraf.

Für gezielte Weiterbildungsprogramme können Gutscheine hilfreich, aber auch schädlich sein. Bisherige Ergebnisse lassen darauf schließen, dass Gutscheine allein die Wirksamkeit eines Programms nicht sicherstellen können. Obwohl Gutscheine die Wahlmöglichkeiten der Verbraucher stark erhöhen und die Notwendigkeit staatlicher Aufsicht verringern, führen sie aufgrund unzureichender Informationen und der Abweichung zwischen den staatlichen Zielen und denen des Teilnehmers nicht unbedingt zu optimalen Ergebnissen. Evaluationen von Weiterbildungsprogrammen für sozial benachteiligte und freigesetzte Arbeitnehmer führten zu gemischten Ergebnissen. Viele der Studien ließen erkennen, dass trotz der allgemeinen Beliebtheit von Gutscheinen auf Teilnehmerseite die Wirksamkeit von Gutscheinprogrammen für sozial benachteiligte Teilnehmer oft geringer ist als für Gruppen ohne Gutscheine. Die Befunde für freigesetzte Arbeitnehmer sind gemischt. Wenn diese Gruppe Gutscheine nutzt, können richtige Beratung und Beurteilung sowie Angaben über die Leistungen des Anbieters die Wirksamkeit der Gutscheine verbessern.

Acknowledgement I am grateful to comments provided by Bernd Fitzenberger and Carolyn Heinrich, but they are not responsible for any errors.

\section{References}

Barnow, B.S.: Exploring the Relationship Between Performance Management and Program Impact: A Case Study of the Job Training Partnership Act. J. Policy Anal. Manag. 19(1), 118-141 (2000a) 
Barnow, B.S.: Vouchers for Federal Targeted Training Programs. In: Steurele, E., Ooms, V.D., Peterson, G., Reischauer, R. (eds.) Vouchers and Related Delivery Mechanisms: Consumer Choice in the Provision of Public Services. Brookings Institution Press, Washington DC (2000b)

Barnow, B.S., Aron, L.Y.: Survey of Government-Provided Training Programs. In: Commission on Workforce Quality and Labor Market Efficiency (eds.) Investing in People: A Strategy to Address America's Workforce Crisis, Background Papers, vol. 1. U.S. Department of Labor, Washington DC (1989)

Barnow, B.S., King, C.T.: Improving the Odds: Increasing the Effectiveness of Publicly Funded Training. The Urban Institute Press, Washington DC (2000)

Barnow, B.S., King, C.T.: The Workforce Investment Act in Eight States. U.S. Department of Labor, Employment and Training Administration, Occasional Paper 2005-001, Washington DC (2005)

Barnow, B.S., Smith, J.: Performance Management of U.S. Job Training Programs: Lessons from the Job Training Partnership Act. Publ. Finance Manag. 4(3), 247-287 (2004)

Bednarzik, R.W., Jacobson, L.: Labor Training Policy in an Increasingly Competitive World but Shrinking Federal Budgets. Unpublished manuscript (1996)

Christopherson, G.: Locating, Enrolling, and Maintaining the Sample. In: SRI International (eds.) Final Report of the Seattle-Denver Income Maintenance Experiment, vol. 1. Design and Results. SRI International, Menlo Park CA (1983)

Corson, W., Decker, P., Gleason, P., Nicholson, W.: International Trade and Worker Dislocation: Evaluation of the Trade Adjustment Assistance Program. Mathematica Policy Research, Princeton NJ (1993)

Dickinson, K.P., West, R.W.: Impacts of Counseling and Education Subsidy Programs. In: SRI International (eds.) Final Report of the Seattle-Denver Income Maintenance Experiment, vol. 1. Design and Results. SRI International, Menlo Park CA (1983)

Garfinkel, I.: Is In-Kind Redistribution Efficient? Q. J. Econ. 87(2), 320-330 (1973)

Heckman, J.J., Heinrich, C., Smith, J.: The Performance of Performance Standards. J. Hum. Resour. 37(4), 778-811 (2002)

McConnell, S., Stuart, E., Fortson, K., Decker, P., Perez-Johnson, I., Harris, B., Salzman, J.: Managing Customers' Training Choices: Findings from the Individual Training Account Experiment. Mathematica Policy Research, Washington, DC (2006)

Mikelson, K.S., Smith Nightingale, D.: Estimating Public and Private Expenditures on Training in the United States. The Urban Institute, Washington DC (2004)
National Governors Association: A Governor's Guide to Creating a $21^{\text {st }}$ Century Workforce. National Governors Association Center for Best Practices, Washington DC (2002)

Niskanen, W.: Bureaucracy and Representative Government. Aldine Publishing Company, Chicago (1971)

Osborne, D., Gaebler, T.: Reinventing Government: How the Entrepreneurial Spirit is Transforming the Public Sector. AddisonWesley Publishing Company, Reading MA (1992)

Public Policy Associates: U.S. Department of Labor Career Management Account Demonstration Project Evaluation Final Report. Public Policy Associates, Lansing MI (1998)

Snyder, T.D., Dillow, S.A., Hoffman, C.M.: Digest of Education Statistics, 2007. U.S. Department of Education, Washington DC (2008)

Social Policy Research Associates: The Workforce Investment Act after Five Years: Results from the National Evaluation of the Implementation of WIA. Social Policy Research Associates, Oakland CA (2004)

Stanley, M., Katz, L., Krueger, A.: Developing Skills: What We Know about the Impact of American Educational and Training Programs on Employment, Earnings, and Educational Outcomes. Harvard University Department of Economics, Cambridge MA (1998)

Trutko, J., Barnow, S.: Vouchers under JTPA: Lessons for Implementation of the Workforce Investment Act. James Bell Associates, Arlington VA (1999)

U.S. General Accounting Office: Multiple Employment Training Programs: Information Crosswalk on 163 Employment Training Programs. U.S. General Accounting Office, Washington DC (1995)

U.S. General Accounting Office: Millions Spent to Train Students for Oversupplied Occupations. Report GAO/HEHS-97-104. U.S. General Accounting Office, Washington DC (1997)

Burt S. Barnow, 1973 Ph. D., Economics, University of Wisconsin at Madison; 1973-1975 Assistant Professor of Economics, University of Pittsburgh; 1975-1977 Economist at the Office of the Assistant Secretary for Policy, Evaluation, and Research, U.S. Department of Labor; 1977-1979 Special Assistant to the Deputy Assistant Secretary, Office of the Assistant Secretary for Policy, Evaluation, and Research, U.S. Department of Labor; 1979-1984 Director of the Office of Research and Evaluation, Employment and Training Administration, U.S. Department of Labor; 1984 Economic consultant for the government of Australia; 1984-1992 Vice President and Project Manager of LewinICF; Since 1992: Associate Director for Research and Principal Research Scientist, Institute for Policy Studies, Johns Hopkins University.

Fields of interest: Evaluation of active labour market policies and other social programs, analysis of occupational labour market shortages, and analysis of child support guidelines policies. e-Mail: barnow@jhu.edu 